\title{
ANIMALES Y «NARRATIVIDAD». DOS MUESTRAS PARA UN BESTIARIO EN LA LÍRICA DE DOS GENERACIONES ESPAÑOLAS CONTEMPORÁNEAS
}

\author{
Joaquín Moreno Pedrosa \\ Universidad de Sevilla
}

\section{RESUMEN}

Tal como señala Robert Langbaum en The poetry of experience, desde finales del siglo XVIII la poesía europea va incorporando rasgos característicos de la narrativa y el drama, con el fin de distanciar la perspectiva del sujeto lírico y tratar de convertir su experiencia en un hecho empírico. Por lo que respecta al panorama poético español, los animales son uno de los referentes que con mayor frecuencia sirven como correlato objetivo, para representar tanto sentimientos o revelaciones subjetivas como lugares, épocas y otros elementos externos a la propia conciencia lírica. Su presencia va acompañada siempre de rasgos narrativos en el poema, como demuestra una selección de ejemplos en dos generaciones poéticas. Palabras Clave: Poesía española contemporánea, poesía de la experiencia, intimismo, animales, objetivación poética.

\section{ABSTRACT}

As it is highlighted by Robert Langbaum in The poetry of experience, since the end of the Eighteenth Century, European poetry started including characteristics of fiction and drama in order to separate the perspective of the lyrical subject and transform its experience into an empirical fact. Regarding the Spanish poetic outlook, animals are one of the most frequently used referents as objective correlative, so as to represent feelings and subjective revelations as places, times and other elements out of the lyrical subject. Its presence is always accompanied by narrative features in the poem, as it is seen in a variety of examples from two poetic generations.

KEY WORDS: Contemporary Spanish poetry, poetry of experience, intimism, animals, poetic objectivation.

\section{INTRODUCCIÓN: THE POETRY OF EXPERIENCE EN ESPAÑA}

En su obra The poetry of experience. The dramatic monologue in modern literary Recibido: 20-01-2016 / Aceptado: 15-07-2016 
tradition, Robert Langbaum describe toda la lírica occidental posterior a la Ilustración como inscrita en una tradición, denominada por él «poesía de la experiencia», que trata de superar la separación establecida por el empirismo entre los hechos y su valoración, partiendo de «aquello que percibimos en los instantes de experiencia inmediata, sin ayuda del análisis» (p. 78). De aquí procede tanto la búsqueda de la objetividad de este tipo de poesía como su estilo antirretórico, «que es en sí mismo una retórica» (p. 92). Se trataría de:

una poesía edificada sobre el equilibro deliberado entre experiencia e idea, una poesía que se enuncia no como una idea, sino como una experiencia de la que pueden abstraerse una o más ideas como racionalizaciones problemáticas (p. 95).

Este tipo de poesía, que Langbaum rastrea hasta las Lyrical Ballads (1798) de Wordsworth" ${ }^{1}$ cifra su contribución en que "fusiona los elementos de pensamiento, sentimiento, y objeto percibido» (p. 102), que en la poesía anterior estaban solo yuxtapuestos, de modo que la validez de sus ideas no está en función de un sistema público de valores sino de «la experiencia genuina de una persona concreta» (p. 111). Esta persona no tiene que coincidir necesariamente con el autor del poema, sino que es un observador que «busca fuera de sí la experiencia de su poema» para «desarrollar un alma o identidad» (p. 116), que llega a identificarse con el propio poema; por tanto, según Langbaum, habría que considerarlo más bien «un personaje en una acción dramática, un personaje al que el poeta asigna las cualidades necesarias para que el poema le ocurra» (p. 119), en un ámbito donde confluyen los rasgos de los géneros literarios lírico y dramático (p. 313). El ejemplo más claro de esta perspectiva se localiza en los monólogos dramáticos publicados por Browning y Tennyson en 1842; en ellos, la atribución de la voz poética a personajes moralmente reprobables obedece al deseo de «establecer la relación simpática del lector con el poema»², creando una tensión entre la perspectiva directa del personaje y las ideas morales socialmente adoptadas por el lector. Ambos resultarían, entonces, tanto agentes como espectadores de la trama ( $\mathrm{p}$. 330), y quedaría anulada en el ámbito del poema la distinción entre asunto, poeta y lector, pues el asunto es «aquello que el poeta engendra», y el lector «debe convertir el poema en fruto de su propia mente» (p. 370). En los monólogos dramáticos que componen The ring and the book, de Browning, descubre Langbaum una superación de la dicotomía entre el poeta mimético y el demiúrgico: «el poeta solo manipula hechos existentes», pero «el significado que produce no es una realidad que preexistiese al poema como un objeto a imitar» (p. 234), ya que la poesía de la experiencia es «una literatura que se vuelve sobre sí misma, generando sus valores propios» (p. 362).

\footnotetext{
${ }^{1}$ Langbaum, R., La poesía de la experiencia. El monólogo dramático en la tradición literaria moderna, Julián Jiménez Heffernan (trad.), Granada, Comares, 1996, p. 124.

${ }^{2}$ Langbaum, R., La poesía de la experiencia [...], ob. cit., p. 155. 
Animales y «narratividad». Dos muestras para un bestiario en la lírica de dos generaciones españolas...

La influencia de la obra de Langbaum está documentada en España, sobre todo, a partir de Jaime Gil de Biedma, quien lo cita en $1959^{3}$. En cambio, la definición que muchos críticos han trazado de una parte de la poesía española de posguerra como «poesía de la experiencia» frecuentemente no tiene en cuenta los postulados de Langbaum, tal como Gil de Biedma los aplicó a su propia obra; lo más común es definir esta opción estética como una poesía descriptiva de contenido autobiográfico. Es el caso de José Olivio Jiménez cuando dice que, por la «relación literal entre experiencia y palabra poética», «los poetas del 50 fueron y son, todos, poetas de la experiencia ${ }^{4}$. Tampoco es raro que estudiosos conscientes del proceso de construcción de una identidad poética que significa este tipo de poesía, como Elena Barroso, la definan, de una forma que puede llevar a confusión, como una «reflexión generalizadora de la anécdota personal y biográfica del poeta $»^{5}$. En cambio, otros estudiosos del panorama poético de estos años sí han basado sus análisis en el conocimiento de la obra de Langbaum. Así, María Victoria Utrera observa que los postulados de Langbaum solo son heredados por lo que actualmente se denomina «poesía de la experiencia» cuando «se entiende esta como experiencia de un sujeto real desdoblado y se separan el yo poético y el real» ${ }^{6}$. Por su parte, el retorno a la anécdota personal ha llevado a Juan José Lanz a hablar de «nuevo romanticismo» al referirse a esta poesía ${ }^{7}$. Sin embargo, este crítico precisa que su autor suele distanciarse del «yo» mediante cierta ficción autobiográfica, para evitar el patetismo, y elige un tono narrativo, con un desarrollo lógico de principio a fin (p. 38). Según Lanz, hay en muchos de estos poemas consciencia de la ficcionalización de la vida que supone la literatura, de la diferencia entre poesía y realidad (p. 39); de hecho, el poema constituye la materialización de «la distancia entre el yo del poeta y la persona literaria, el yo poético, que se conforma en el texto a través del lenguaje», y este es uno de los rasgos que más acercan a estos poetas a la generación del $50^{8}$. A esto se refiere César Nicolás cuando habla de una revalorización de «la anécdota y el autobiografismo lírico — solo que se hacen simbólicos, y son tratados de diferente forma» ${ }^{9}$. Es José Luis García Martín quien mejor lo resume, cuando afirma:

\footnotetext{
${ }^{3}$ Salvador, A., «The poetry of experience y la poesía española de los últimos quince años», en Langbaum, R., La poesía de la experiencia. El monólogo dramático en la tradición literaria moderna, Julián Jiménez Heffernan (trad.), Granada, Comares, 1996, p. 11.

${ }^{4}$ Jiménez, J. O., «Reafirmación, proximidad, continuidad: notas hacia la poesía española última (19751985)», en Las nuevas letras, 3-4 (1985), p. 45.

${ }^{5}$ Barroso, E., Poesía andaluza de hoy (1950-1990), Sevilla, Biblioteca de Cultura andaluza, 1991, p. 18.

${ }^{6}$ Utrera Torremocha, M. V., «Luis Cernuda en la poesía española del siglo xx», en VV. AA., A zaga de tu huella. Homenaje al profesor Cristóbal Cuevas, Málaga, Universidad de Málaga, 2005, vol. II, p. 144.

${ }^{7}$ Lanz, J. J., «La poesía española: ¿hacia un nuevo romanticismo?», en El Urogallo, 60 (1991), p. 37.

${ }^{8}$ Lanz, J. J., «Primera etapa de una generación. Notas para la definición de un espacio poético: 19771982», en Ínsula, 565 (1994), p. 5.

${ }^{9}$ Nicolás, C., «Novísimos (1966-1988): Notas para una poética», en Ínsula, 505 (1989), p. 4.
} 
No toda poesía es autobiográfica, según quieren los lectores ingenuos, pero buena parte de la poesía más reciente sí lo es. Hay que tener en cuenta, sin embargo, que el «yo real» queda en cualquier caso fuera del papel; el personaje que dice «yo» en el poema - autobiográfico o no - es siempre una creación artística, un artificio verbal $^{10}$.

En este diseño de un yo lírico diferente del poeta ha visto Elena Barroso la diferencia de este «neorromanticismo» frente al romanticismo clásico ${ }^{11}$; esta «voluntad objetivadora», como la ha llamado Miguel d'Ors, iría acompañada de «una rigurosa exigencia estética», «una elaboración formal y una contención expresiva - manifiesta en rasgos como la métrica tradicional, el lenguaje sobrio o el prosaísmo» ${ }^{12}$. Lanz ha señalado, como otros rasgos de este tipo de poesía, la recuperación de la memoria como fundamento de la escritura, el desplazamiento de la atención desde el texto poético y su relación con la realidad hasta la experiencia misma y su representación, y el tono medio ${ }^{13}$. Sin embargo, está claro que el nombre de «poesía de la experiencia», que su inventor utilizó para designar la perspectiva desde la que se han elaborado las obras de la tradición literaria occidental a partir del siglo XVIII, no es adecuado para designar una manifestación poética española en auge desde finales de los setenta. Es por eso que, buscando un término menos equívoco, José Luis García Martín denominó a esta corriente «poesía figurativa» ${ }^{14}$, frente a la poesía surrealista o la minimalista.

En este trabajo se han recogido varios ejemplos en que los procedimientos objetivadores descritos por Langbaum, y asumidos por cierto sector de la crítica española, se han establecido alrededor del animal como motivo literario. La selección procede de dos generaciones poéticas concretas: la que se suele considerar como referente para la poesía actual, la llamada «generación del 70» (autores nacidos entre 1939 y 1953), y la generación siguiente, que incluye a los que nacieron entre 1954 y 1968. Para esta selección, se han excluido aquellos usos simbólicos y metafóricos en que el animal ya poseía un valor literario preestablecido (piénsese en el toro para la poesía de García Lorca o Miguel Hernández, el ruiseñor para la de Juan Ramón Jiménez, etc.), y se han preferido ejemplos en que el animal aparece como objeto de experiencia directa para el sujeto poético, en un equivalente de la anécdota y el protagonista del monólogo dramático que subrayaba Langbaum, como medio de objetivación de un sentimiento,

\footnotetext{
${ }_{10}$ García Martín, J. L., La poesía figurativa. Crónica parcial de quince años de poesía española, Sevilla, Renacimiento, 1992, p. 29. A este respecto, puede verse también García Montero, L., «De la poesía como género de ficción», en Aguas territoriales, Valencia, Pre-Textos, 1996, pp. 13-32.

${ }^{11}$ Barroso, E., Poesía andaluza de hoy (1950-1990), ob. cit., p. 46.

${ }^{12}$ Ors, Miguel D', La aventura del orden. Poetas españoles del fin de siglo, Sevilla, Renacimiento, 1998, p. 102.

${ }^{13}$ Lanz, J. J., Antología de la poesía española (1960-1975), Madrid, Espasa-Calpe, 1997, p 67.

${ }_{14}$ García Martín, J. L., La poesía figurativa. Crónica parcial de quince años de poesía española, Sevilla, Renacimiento, 1992, pp. 208-227.
} 
Animales y «narratividad». Dos muestras para un bestiario en la lírica de dos generaciones españolas...

una idea o una intuición. Más concretamente, se han limitado las referencias a aquellas en que el animal aparece para sustentar una evocación del pasado, o bien para objetivar un contenido intuitivo. Esta restricción temática a solo dos muestras obedece a un doble motivo: la necesidad de acotar y organizar el ámbito de estudio, dada la vastedad de su alcance, y el deseo de subrayar su continuidad con dos de las figuras fundamentales en la poesía de posguerra, como son Vicente Aleixandre y Dámaso Alonso. Los dos usos en que nos hemos centrado pueden rastrearse hasta la obra de estos autores, donde aparecen ya claramente representados.

\section{Los ejemplos de Dámaso Alonso y Vicente Aleixandre}

La abundancia de referencias a la fauna es, precisamente, una de las características más significativas de la poesía de Aleixandre. Ya Claudio Rodríguez, en un famoso artículo, había revisado el «bestiario» que recorre la obra del poeta sevillano, desde el «Pájaro de la noche» de su primer libro, Ámbito, hasta el toro de Diálogos del conocimiento ${ }^{15}$, con una mención especial a la vida submarina de los espacios abisales que aparece en La destrucción o el amor. Pero, tal vez, el ejemplo más claro de su visión simbólica de la naturaleza, cuyos elementos remiten a una realidad más profunda, sea el poema «El escarabajo»:

He aquí que por fin llega al verbo también el pequeño escarabajo, tristísimo minuto, lento rodar del día miserable, diminuto captor de lo que nunca puede aspirar al vuelo.

[...]

El dulce escarabajo bajo su duro caparazón que imita a veces algún ala, nunca pretende ser confundido con una mariposa, pero su sangre gime (caliente término de la memoria muerta) encerrada en un pecho con no forma de olvido, descendiendo a unos brazos que un mundo oscuro crean ${ }^{16}$.

Como puede verse en este ejemplo de Aleixandre, el animal sirve para objetivar un contenido intuitivo, la revelación de lo pequeño, de lo olvidado, de todo aquello que no se realiza plenamente («tristísimo minuto», «día miserable», «lo que nunca puede aspirar al vuelo»). Por lo que respecta a la poesía de Dámaso Alonso, encontramos en ella un uso similar de la fauna; por ejemplo, como imagen del terror existencial en el poema titulado $«$ Los insectos» ${ }^{17}$, una visión de pesadilla de la multitud de diminutos

\footnotetext{
${ }^{15}$ Rodríguez, C., «Algunos comentarios sobre el tema de la fauna en la poesía de Vicente Aleixandre», en Ínsula, 374-375 (1978), p. 17.

${ }^{16}$ Aleixandre, V., Poesías completas, Madrid, Visor, 2001, pp. 400-401.

${ }^{17}$ Alonso, D., Hijos de la ira, Madrid, Espasa Calpe, 1991, pp. 400-401.
} 
seres que revolotean en torno a la luz en una noche de verano. Otra intuición objetivada en un motivo animal es el hermoso poema místico titulado «El alma era lo mismo que una ranita verde». En él, el alma se identifica con una rana al borde de un anchuroso río, que se debate entre el deseo de sumergirse en su elemento, y el miedo de perder el control en su inmersión:

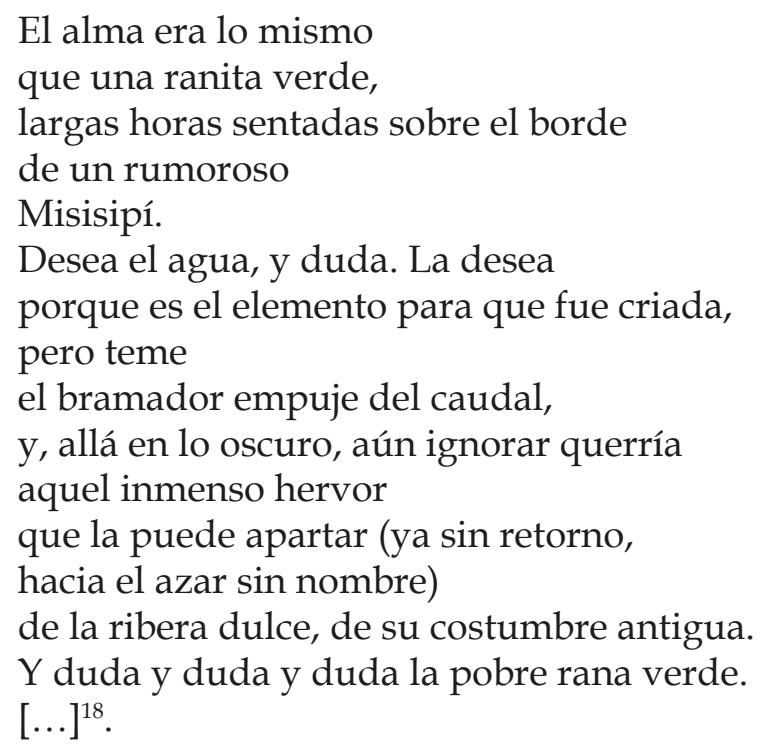

La corriente de agua, tal como desvela el final del poema, sería la propia divinidad: «¡Ay, Dios, / cómo me has arrastrado, / cómo me has desarraigado, / cómo me llevas / en tu invencible frenesí, / cómo me arrebataste / hacia tu amor!» ${ }^{19}$. En este caso, el correlato animalesco induce y facilita la simpatía y la identificación del lector con el impulso religioso del sujeto lírico, que ve corregido de esta forma lo que de otra distinta podría constituir un exceso de patetismo.

$\mathrm{Si}$, en los ejemplos propuestos, tanto el escarabajo de Aleixandre como los insectos y la rana de Dámaso, los animales sirven para objetivar una experiencia intuitiva, en la poesía de este último encontramos también un ejemplo en que uno de ellos actúa como desencadenante de una evocación del pasado. Parece inevitable pensar en la magdalena de Proust, por más que la conjunción de ambos correlatos no resulte muy apetecible; ya que, en el caso de Dámaso Alonso, se trata de la «Elegía a un moscardón azul». La descripción del insecto que lleva a cabo el poeta madrileño está sorprendentemente llena de admiración y ternura, a pesar de haberlo matado él mismo: «[...] me acerqué hasta ti: eras muy bello. / Grandes ojos oblicuos / te coronan la frente, / como un turbante de oriental monarca. / Ojos inmensos, bellos ojos pardos $[\ldots] »^{20}$. Mientras contempla el moscardón, el sujeto lírico establece un flujo de simpatía

\footnotetext{
${ }^{18}$ Alonso, D., Hijos de la ira, ob. cit., p. 133.

${ }^{19}$ Alonso, D., Hijos de la ira, ob. cit., p. 134.

${ }^{20}$ Alonso, D., Hijos de la ira, ob. cit., p. 113. 
Animales y «narratividad». Dos muestras para un bestiario en la lírica de dos generaciones españolas...

tan estrecho con él que, por un momento, llega a haber un instante de identificación entre ambos, más concretamente entre el insecto y el «yo» niño del poeta:

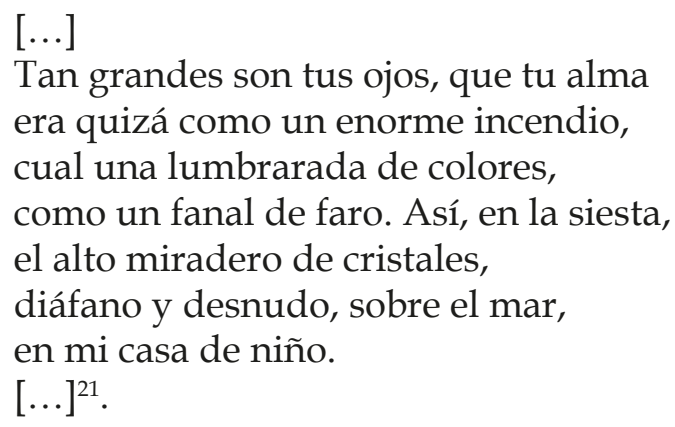

Este momento de identificación es el que sustenta toda la posterior reflexión existencialista que el sujeto lírico dirige al insecto muerto, reflexión que, de otro modo, resultaría un tanto chocante, y tal vez teñida de un exceso de patetismo si el poeta se la aplicara a sí mismo en primera persona. Sin embargo, al objetivarse en el pequeño moscardón, el poema resulta equilibrado, y el lector no encuentra obstáculos para asumir la experiencia que en él se contiene, ni por lo insólito de su asunto ni por el intimismo del autor.

\section{LOS ANIMALES Y LA EVOCACIÓN DEL PASADO}

Los ejemplos propuestos establecen dos líneas generales que se prolongarán en los motivos líricos animalescos hasta nuestros días: su uso para sustentar una evocación del pasado, o bien para objetivar un contenido intuitivo. En «Bajar al perro», el poeta Jesús Munárriz, ya en la llamada «generación del 70», convierte la figura del perro doméstico en el símbolo de la continuidad entre el pasado («[...] ojos de perro fiel, / me acompañaban / en mi lejana infancia») y el presente que lo evoca:

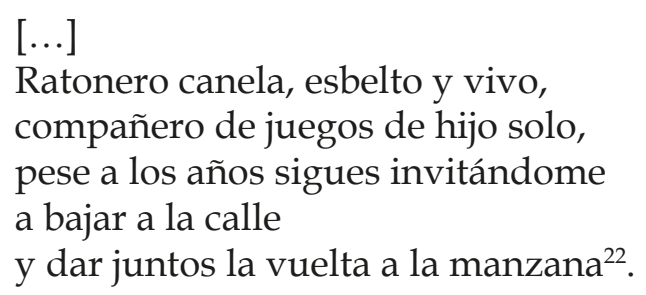

Hay otro ejemplo en el que este animal se utiliza para hacer presente una experiencia pretérita; nos referimos al poema «En la tumba de Joker», una libre adaptación que Luis Alberto de Cuenca hace del poema The House Dog's Grave, de Robinson Jeffers. Aunque los procedimientos empleados, el motivo principal y su función han sido importados directamente del original americano, tal vez no sea del

\footnotetext{
${ }^{21}$ Alonso, D., Hijos de la ira, ob. cit., p. 113.

${ }^{22}$ Munárriz, J., Poética y poesía, Madrid, Fundación Juan March, 2007, p. 104.
} 
todo inapropiado traerlo a colación aquí, puesto que el autor madrileño ha convertido a Haig, el original bulldog inglés del poema, en un golden retriever llamado Joker, trascendiendo de esta manera el mero ejercicio traductológico. Se trata de una obra muy interesante desde el punto de vista de nuestro estudio, ya que, tanto el original como la adaptación, son monólogos dramáticos, con la peculiaridad de que, en este caso, el personaje que los pronuncia es el propio perro. $Y$, por si este hecho no fuera ya bastante sorprendente, se da también la peculiaridad de que el perro está muerto, y les habla a sus amos desde el otro mundo. Ambas circunstancias son, en efecto, bastante chocantes, y podrían parecer obstáculos serios a la hora de obtener el asentimiento del lector. Sin embargo, veremos cómo ambas cooperan eficazmente para lograr este fin. El poema expresa la devoción del difunto Joker por sus dueños humanos: ante la constatación, por ejemplo, de que él ya ha muerto, aclara que «no hubiera soportado / que vosotros lo hicierais antes». El perro también agradece y celebra el afecto que recibió durante su vida por parte de sus dueños humanos («En este sueño / perpetuo que es la muerte, os sueño a todas horas, / recordando el amor y la fe que me disteis»). Estos sentimientos se prolongan hasta más allá de su defunción, y alimentan la existencia ultraterrena de Joker:

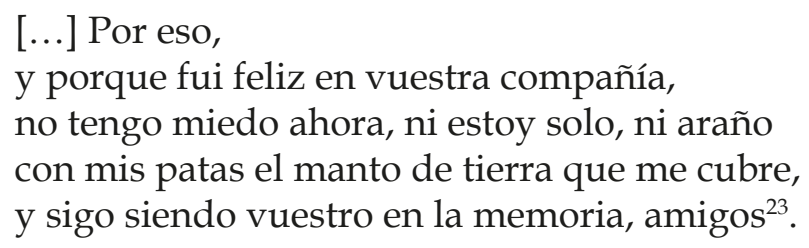

Devoción y gratitud son, efectivamente, los dos atributos más característicos del perro como animal de compañía. En este poema, ambos aparecen aumentados al máximo, prolongándose incluso más allá de la muerte. Y, ante la pérdida de un fiel compañero, ¿qué mejor manera de celebrar sus virtudes y el tiempo transcurrido en su compañía que haciendo que él mismo los pondere? Al poner en sus propias palabras la evocación del pasado, ningún exceso subjetivista o sentimental hace dudar de su autenticidad y pureza; la vida compartida queda objetivada en el correlato más incuestionable de dicha experiencia, que es el propio animal. Los rasgos del poema que, en un principio, más chocantes resultaban por su originalidad, son precisamente los que más eficazmente han ayudado a conseguir su efecto, haciendo que el lector comparta el emocionado recuerdo del compañero perdido.

Por razones evidentes, el perro constituye una elección frecuente en los poemas que se refieren a la infancia. Sin embargo, hay un caso en que el motivo animal sirve de sustento, no solo a una evocación del pasado, sino también a una reflexión metapoética. Nos referimos a la composición titulada «Murió el "León”», del poeta gallego Miguel

\footnotetext{
${ }^{23}$ Cuenca, Luis Alberto de, Por fuertes y fronteras, Madrid, Visor, 1996, p. 67.
} 
Animales y «narratividad». Dos muestras para un bestiario en la lírica de dos generaciones españolas...

d'Ors. Con la noticia de la muerte del perro, compañero de juegos en la niñez, el autor toma conciencia de los muchos años que lo han ido alejando «de su ladrido tenso, allí, en la punta / de la cadena, junto / a aquel portón de líquenes antiguos / por el que nuestros pasos deslumbrados / entraban al verano». Los rasgos físicos y los juegos del animal desaparecido se convierten en símbolo de la infancia perdida, antes de que el poema llegue a su conclusión y revele una verdad inesperada:

$[\ldots]$

Se nos fue con el tiempo.

Ya nunca cruzará por nuestros juegos.

Qué extraño ese vacío que aún sujeta, oxidada, su cadena.

Pero nos ha quedado

la palabra: miradlo cómo aceza, cómo mueve la cola en estos versos ${ }^{24}$.

El perro real, evocado en los años de la infancia, ha sido sustituido por su doble literario, creación del autor a través de la palabra; y este animal ya no morirá, vivo por siempre en los versos que lo recuerdan. No es la única vez en la poesía de d'Ors en que la fauna sirve para objetivar un retorno del pasado, y queda a su vez preservada en un poema. En «Urracas de Egham Hill», varios de estos pájaros aparecen ante el poeta en un paraje inglés, y a través de la rememoración logran fundir el recuerdo de la niñez y el paraje extranjero: «sentí que habíais venido desde mi infancia -viejos / campos de Cotobade...- y por vosotras / aquel rincón ajeno fue un instante mi mundo». La representación poética de las aves, así como la reflexión metaliteraria sobre la perdurabilidad del arte, en este caso no está exenta de un sentimiento de gratitud: «urracas de Egham Hill, quiero dejaros / para siempre volando en estos versos» ${ }^{25}$. Hay un ejemplo muy similar en la obra del poeta murciano Eloy Sánchez Rosillo, también centrado en el motivo de un ave, en el poema que se titula «Acerca del jilguero». En esta composición, el autor nos hace saber «que de todos los pájaros que yo he visto y oído / el más mío de todos es sin duda el jilguero». El motivo de esta identificación es muy claro, y se nos hace saber en los versos siguientes:
$[\ldots]$
Cuando digo su nombre mi infancia entera vuelve, y desando el camino y de nuevo retorno a aquella casa blanca cuyos muros se alzaban en medio de los campos, en el centro del corazón del mundo y del verano. Y me veo a mí mismo en la mañana de oro -igual que en el comienzo prometedor de un mito- por vez primera oyendo un canto que venía

\footnotetext{
$\overline{{ }^{24} \text { Ors, Miguel D', }} 2001$ (Poesías escogidas), Sevilla, Cuadernos de Poesía Númenor, 2001, p. 105

${ }^{25}$ Ors, Miguel D', 2001 (Poesías escogidas), ob. cit., p. 278.
} 
de dónde, de qué ser maravilloso y puro.

$[\ldots]^{26}$

El jilguero constituye para el poeta la evocación precisa y completa de la infancia, ya que fue a esa edad la primera vez que escuchó su canto. Y, hasta aquí, nada distinguiría este poema de cualquier otra rememoración del pasado, llevada a cabo a partir de un estímulo presente, de no ser por ese «Y me veo a mí mismo», que adelanta el contenido de los siguientes versos. Pues, en efecto, a partir de este punto el protagonista del poema será el propio autor de niño, al cual se dirigirá su «yo» del presente en segunda persona: «Escucha, escucha, niño, y acércate despacio / al lugar del que brota sin cesar / esa música hermosa ${ }^{27}$. En los versos siguientes se describe el acercamiento del niño al tronco del almendro de donde procede el canto, y su búsqueda desde el suelo de la fuente del sonido, al tiempo que se le anima a proseguir y se le dan consejos para realizar la tarea. El autor del poema aparece entonces totalmente desdoblado de su «yo» infantil, como puede observarse en estas palabras: «[...] No te muevas, y observa / con atención. Insiste. Sí, ya veo, parece / que algo se está moviendo en esa rama ${ }^{28}$. A través de este juego de perspectivas, Sánchez Rosillo consigue convertir su evocación infantil en un personaje autónomo, totalmente objetivado, cuyo vínculo con el «yo» actual del autor y con el lector es el jilguero que entona su canto en lo alto del árbol, como vehículo de la experiencia. Los lectores, que estamos participando de esa experiencia junto al propio poeta, la asumimos como propia, de manera que, cuando este la celebra en el momento presente, ningún exceso de subjetividad ni patetismo nos impide asentir al contenido anímico de sus afirmaciones:

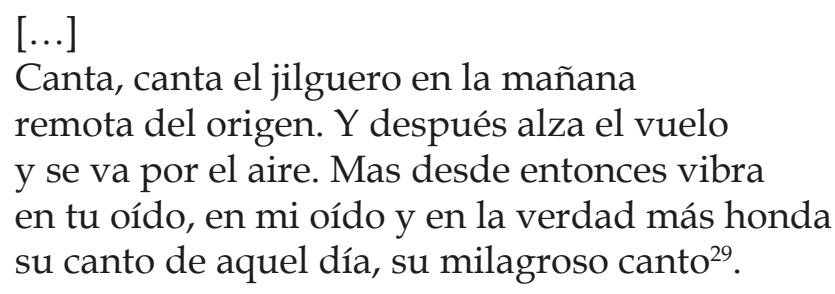

En la siguiente generación de poetas, encontramos varios ejemplos de evocación del pasado objetivada en animales en la obra del autor granadino José Julio Cabanillas. En el primero de ellos, el animal elegido es la golondrina. Es inevitable recordar el modelo de Bécquer y, dadas las costumbres migratorias de estas aves, pensar que nos hallamos ante un símbolo consolidado en la literatura. Sin embargo, en el ejemplo que nos ocupa, no se trata únicamente de una metáfora del paso del tiempo. La llegada y

\footnotetext{
${ }^{26}$ Sánchez Rosillo, E., La certeza, Barcelona, Tusquets, 2005, p. 13.

${ }^{27}$ Sánchez Rosillo, E., La certeza, ob. cit., p. 13.

${ }^{28}$ Sánchez Rosillo, E., La certeza, ob. cit., pp. 13-14.

${ }^{29}$ Sánchez Rosillo, E., La certeza, ob. cit., p. 14.
} 
Animales y «narratividad». Dos muestras para un bestiario en la lírica de dos generaciones españolas...

la marcha de las golondrinas marcan el inicio de dos nuevas estaciones, y por tanto el final de las anteriores. Pero, en realidad, como se manifiesta al final del poema, la visión de estos pájaros es la comprobación empírica que tiene el poeta del sentimiento de su propia pérdida, extraviado en los años sucesivos:

Primeras tardes lentas.

Alborotaba el patio su negra algarabía

escribiendo en el aire: Eh, todo comienza.

En las tardes plomizas de febrero

mirábamos sus nidos, vacíos y silenciosos,

esperando su vuelta.

Por dónde andarán hoy, qué habrá sido de ellas.

Y qué ha sido de $\mathbf{m i ́}^{30}$.

El mismo valor de evocación del paso del tiempo e identificación con el sujeto lírico puede encontrarse en otro poema del mismo autor, «Lorito». De modo análogo al poema de Miguel d'Ors sobre el perro «León», en esta composición de Cabanillas se nos ofrece primero el ave real recordada: «Brincaba en su jaula el loro / -disparatados colores / y dichos saludadores- / gritando: “Del caño al coro..." / Y jamás se confundía». Sin embargo, en este poema no hay distinción explícita ni transición entre el loro real y su recreación literaria; cuando el poema termina, comprobamos que estábamos ante un fantasma urdido por la elaboración artística del autor, un objeto que sirve para plantear con distanciamiento su percepción del transcurso del tiempo: «Hoy que se apaga mi día / a este confín de los años / cruzan briznas de su canto / -verde, colorín y espanto- / y me grita: “Eh, viejo extraño" ${ }^{31}$.

\section{LOS ANIMALES Y LA INTUICIÓN OBJETIVADA}

Aparte de la evocación del pasado, la otra vía abierta por los ejemplos de Aleixandre y Dámaso es la objetivación de experiencias intuitivas, más difíciles de definir o transmitir de forma unívoca. En estos casos, el papel de los animales como instrumentos de objetivación poética resulta mucho más relevante, pues ya no se trata de una anécdota extrapolable a otros elementos cualesquiera, como podía ocurrir en el caso de los recuerdos de la infancia, sino que la experiencia poemática está indisolublemente vinculada al animal específico que se adopta como correlato objetivo. En algunas ocasiones, la intuición que se transmite es fácilmente identificable, aunque no aparezca mencionada -ni siquiera indirectamente- en el poema. Es lo que ocurre con «La diferencia estriba en que el vencejo», del poeta salmantino Aníbal Núñez:

La diferencia estriba en que el vencejo

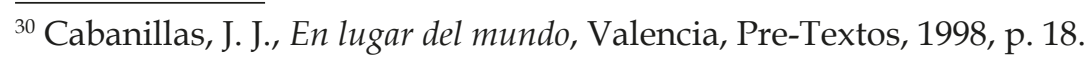

${ }^{31}$ Cabanillas, J. J., Los que devuelve el mar, Valencia, Pre-Textos, 2005, p. 15.
} 


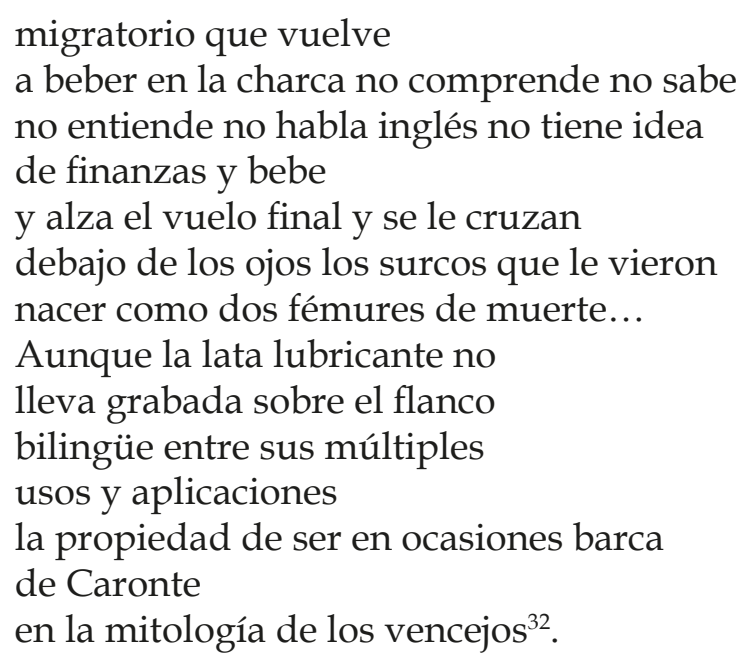

Evidentemente, estos versos contienen una denuncia de la contaminación de la naturaleza por el hombre y, en un nivel más profundo, los sentimientos de rabia frustrada y compasión que ello provoca. Sin embargo, no hay en este poema ninguna marca de primera persona, sustantivos o verbos que se refieran a esos estados psicológicos, ni siquiera una referencia que nos permita suponer que la voz poética ha sido testigo de los hechos que enuncia. En vez de eso, tenemos, por un lado, el comienzo in medias res («la diferencia estriba...»), como si el poema hubiera aparecido en mitad de una conversación; y, por otro, el tono narrativo, centrado en las acciones del vencejo y en la descripción de la lata de lubricante. Ello se debe a que, en esta ocasión, los hechos van a ser presentados exclusivamente desde el punto de vista del animal, totalmente ajeno al entorno comercial del que procede el instrumento de su muerte. La lata abandonada se nos aparece así en toda su carencia de sentido, como un objeto absurdo por su desconexión con el mundo natural, hasta el punto de ser totalmente ajena a su función «en la mitología de los vencejos». Del contraste y la desproporción entre este objeto y las consecuencias que acarrea, la muerte de un ave entre «los surcos que le vieron / nacer», procede el efecto que el poema causa en nosotros. No hay en él interpretación de los hechos, conclusión moralizante o expresión patética de los sentimientos: ningún exceso subjetivista por parte del autor impide o dificulta que recibamos la experiencia contenida en sus versos con toda su crudeza, y experimentemos nuestra propia respuesta emotiva.

Lo más frecuente, sin embargo, es que la intuición que ha dado origen al poema no pueda ser identificada de modo tan claro, lo cual aumenta considerablemente sus posibilidades de interpretación. Es lo que ocurre, por ejemplo, con la composición de Miguel d'Ors que se titula «Caballos en la nieve». En ella, el autor recuerda una excursión por una zona boscosa de Navarra, y la irrupción en el paisaje de unos

\footnotetext{
${ }^{32}$ Núñez, A., La luz en las palabras. Antología poética, ed. de Vicente Vives Pérez, Madrid, Cátedra, 2009, p. 210.
} 
caballos al trote: «Bajo el gris invernizo, / por un alto helechal con nieve polvorosa / -todo como una foto en blanco y negro-, / repentinos, al trote, / unos caballos de greñudas crines». En este caso, el autor no propone a quien lo lee ninguna reflexión derivada del espectáculo de los animales en la naturaleza; este aparece descrito en toda su viveza sin extraer de él ninguna consecuencia, poniendo a disposición del lector la experiencia que contiene del modo más objetivo posible, para que sea él quien participe de ella con sus propias intuiciones:

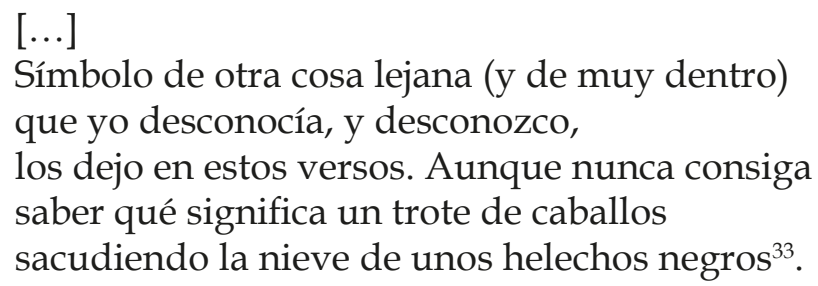

Este tipo de poesía abierta, que no plantea las anécdotas de acuerdo con un curso predeterminado del pensamiento, sino que permite al lector enfrentarse a la objetividad de la experiencia a través de múltiples racionalizaciones simultáneamente posibles, es el ejemplo más claro de la «poesía de la experiencia» descrito por Langbaum. Encontramos un ejemplo muy similar en el poema «Las golondrinas», de Eloy Sánchez Rosillo. En él se nos habla del mes de abril, y de la llegada de las golondrinas. Sin embargo, la presencia de estos pájaros se convierte en algo más que un tópico sobre el retorno de las estaciones, planteando un misterio de interpretación plural acerca de la propia esencia de la primavera, en el que se implica al lector a través de los pronombres «nadie»y «quién», con intención generalizadora:

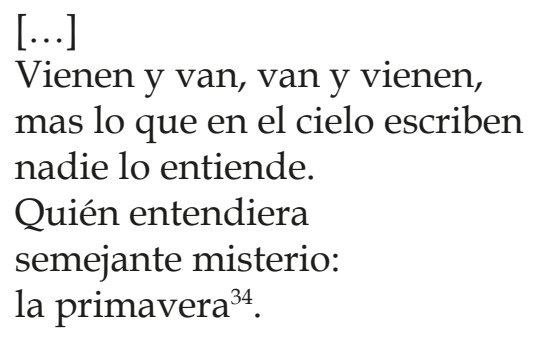

Los pájaros tienen una presencia muy numerosa en la obra de Sánchez Rosillo. En un poeta tan preocupado por el paso del tiempo como el escritor murciano, no es raro que encontremos a uno de estos animales como correlato objetivo de una experiencia temporal. Se trata de otra composición titulada con el nombre de su ave favorita, «El jilguero». Es este un poema narrativo, en el cual se nos presenta al «yo» poético en un atardecer de junio, dirigiéndose en segunda persona a su pequeño hijo mientras este juega en un jardín. Se trata, evidentemente, de un artificio para lograr

\footnotetext{
${ }^{33}$ Ors, Miguel D', 2001 (Poesías escogidas), ob. cit., p. 283.

${ }^{34}$ Sánchez Rosillo, E., Las cosas como fueron, Granada, La Veleta, 1995, p. 151. 
el distanciamiento, puesto que el diálogo es solo una apariencia, tanto por la edad infantil de su fingido interlocutor como por el carácter lírico de la composición en que se lo incluye. Mientras ambos asisten al atardecer, un jilguero se posa en un árbol próximo y entona su canto, llenando «de intimidad la tarde». De repente, el pajarillo alza el vuelo y se pierde de vista. Sin embargo, después de su marcha, las cosas han cambiado sustancialmente:

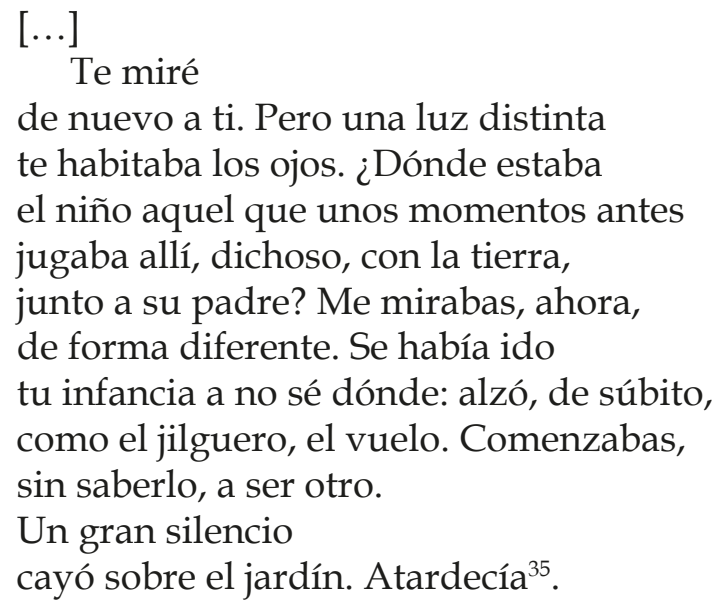

Lo que puede encontrarse en este poema es una intuición, casi adivinatoria: sin mediación de palabra, el padre puede entrever en los ojos de su hijo el primer atisbo de juventud, el primer paso que deja atrás la infancia. Tal experiencia carece, en efecto, de contraste empírico; la intuición podría aparecer ante el lector como puramente subjetiva, ilusoria y carente de fundamento. Sin embargo, al identificarla en el poema con el súbito alzar el vuelo del jilguero, como correlato objetivo, se nos presenta como algo evidente, necesario casi. Y la niñez que se extingue y la avecilla que se aleja quedan identificadas en una unidad simbólica. También puede observarse que, en esta composición, el jilguero tiene una función opuesta a la que recibía en el poema del apartado anterior; si en aquél su canto representaba mejor que nada la infancia del autor, en este su vuelo señala el fin de dicho período para su hijo. Eloy Sánchez Rosillo nos ha dejado otros ejemplos más ligeros de intuiciones objetivadas en animales, como la que encontramos en el poema «Las cigarras». Allí se nos hace una caracterización inesperada de estos insectos, convertidos en un ejemplo de virtud: «Es increíble la tenacidad / que en estas tierras que ganó el verano / exhiben, incansables, las cigarras». Se les atribuye la más firme convicción en el valor de su canto, «que para sí quisieran cuantos tienen / cualquier convencimiento», y se las considera un ejemplo «de laboriosidad indeclinable». La impresión que tenemos de que se está invirtiendo el tradicional valor simbólico de la cigarra, procedente de la famosa fábula, queda confirmada por el propio poeta, quien reconoce no saber «por qué suele decirse / precisamente todo lo contrario» de estos animales, y subraya que «hacen su hermoso

${ }^{35}$ Sánchez Rosillo, E., La vida, Barcelona, Tusquets, 1996, pp. 35-36. 
Animales y «narratividad». Dos muestras para un bestiario en la lírica de dos generaciones españolas...

oficio un día y otro / sin ningún mal humor, con alegría», por contraste con «la cabizbaja seriedad / de la que las hormigas, por ejemplo, / en obedientes filas se envanecen». La conclusión del poema, sin embargo, trasciende el mero diálogo intertextual con la fábula clásica, y está muy lejos de cualquier enseñanza moral o intención didáctica:

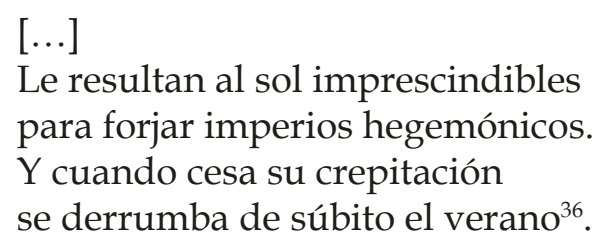

La identificación metafórica entre las cigarras y el verano queda sellada con las imágenes de un sol implacable, sin el cual resulta imposible imaginar el canto de estos insectos, y el hundimiento de la estación cuando este se detiene. El resto del poema, con su disposición argumentativa, sus apartes y su tono a veces incluso prosaico, tenía como misión ir socavando las ideas preconcebidas del lector acerca de estos animales, preparándolo para un lógico final discursivo. En vez de eso, por sorpresa, Sánchez Rosillo termina con una imagen fulgurante, en que la época del año y los animales se fusionan: son las cigarras quienes sostienen el verano.

Entre los poetas de la siguiente generación, uno de los que ha cultivado con más asiduidad este tipo de expresión lírica es el madrileño Julio Martínez Mesanza. Conocido por los correlatos objetivos y monólogos dramáticos de ambientación épica, clásica y medieval, que constituyen el rasgo principal de su obra, Martínez Mesanza ha recurrido también al mundo animal como fuente de motivos para sus poemas. Tal vez el ejemplo más logrado sea la composición titulada «También mueren caballos en combate»:

También mueren caballos en combate, y lo hacen lentamente, pues reciben flechazos imprecisos. Se desangran con un noble y callado sufrimiento. De sus ojos inmóviles se adueña una distante y superior mirada, y sus oídos sufren la agonía furiosa y desmedida de los hombres ${ }^{37}$.

Para las múltiples interpretaciones que puede sugerir este poema, el común denominador parece ser la compasión que suscitan las víctimas inocentes de la violencia humana. Eligiendo una víctima animal, la oposición con el mundo de los hombres es más evidente. El padecimiento de los caballos aparece idealizado (su «noble y callado

\footnotetext{
${ }^{36}$ Sánchez Rosillo, E., La certeza, ob. cit., p. 103.

${ }^{37}$ Martínez Mesanza, J., Europa y otros poemas, Málaga, Área de Cultura de la Diputación Provincial de Málaga, 1990, p. 69.
} 
sufrimiento»), frente al desprecio que provoca el de sus verdugos («la agonía / furiosa y desmedida de los hombres»), y la superioridad moral de las víctimas se subraya explícitamente: «De sus ojos inmóviles se adueña / una distante y superior mirada». Puesto que los caballos suelen ser ignorados en las descripciones de combates, su elección como motivo central resulta especialmente acertada, por lo inesperado; al plantear el enfrentamiento desde su desgraciada experiencia, además, se consigue una crítica más eficaz que a través de cualquier argumentación o razonamiento.

En la misma generación de autores, el poeta José Julio Cabanillas también ha dedicado a un equino un poema lleno de compasión apreciativa, un burro en este caso. La composición, titulada «El burro», está planteada como un monólogo dramático en labios del animal, que enumera momentos de la Historia en los que ha participado uno de su especie. Desde el asesinato de Abel a manos de Caín, perpetrado con una quijada de asno, se suceden las grandes construcciones de la antigüedad en Mesopotamia, Persia y Egipto. El mismo Nilo en que se baña la reina da de beber al animal, que también acompaña al pueblo judío en su éxodo hasta la tierra prometida:

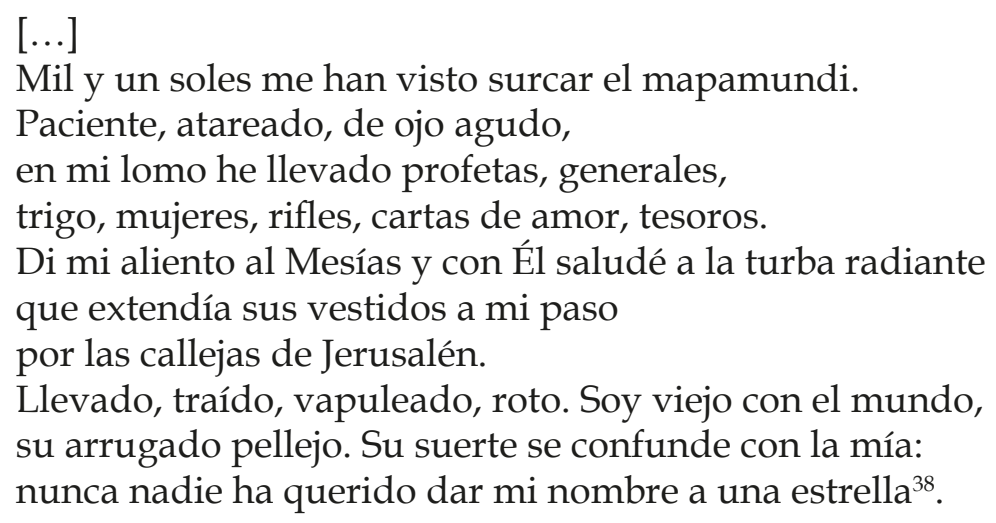

En este poema, el burro aparece como una criatura viejísima, llena de dignidad, silencioso testigo de los momentos cruciales para la humanidad, y sin embargo ignorado, anónimo y olvidado. Pero su propio destino es el del mundo: desempeñar un papel de mero comparsa o escenario de la Historia humana, soportando el trabajo de los hombres, que ni siquiera le prestan atención ni lo distinguen con honor ni agradecimiento alguno. Años más tarde, Cabanillas volverá sobre el mismo tema en un poema en prosa titulado «Los mulos». La caracterización de estos animales es similar a la del burro en el poema anterior, como silenciosos trabajadores anónimos: «Los mulos no tienen nombre. Nadie les llama Lucero como a una novia, ni Alazán como en las coplas». La razón está en su esterilidad, que limita su destino a una vida de trabajo sin fruto, y finalmente la muerte: «Estériles, por eso son sus ojos dos charcos tristes y pasan por la puerta con las testas vencidas igual que girasoles resecos ya, sin

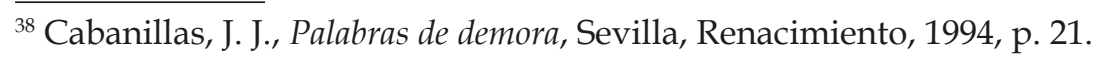


Animales y «narratividad». Dos muestras para un bestiario en la lírica de dos generaciones españolas...

pétalo y en sazón para el corte. Su sombra está maldita». Sin embargo, en este poema la conclusión no es tan melancólica como en «El burro». Más allá de su futuro de trabajo y su esterilidad, el poeta vislumbra los días de la cosecha, el fruto de su labor, la victoria sobre los elementos y la aridez de la tierra, y la fecundidad de la que habrán de beneficiarse muchos otros:

Capitanes sin chispa de talento, barcos varados los doce meses, braceando por salir a flote entre las olas de tierra. Sois la quilla sin rumbo que no sigue a la estrella. Sois la tarde aburrida, la verbena sin música, la chica fea, el suicida que duda en el último momento. Sois cualquiera de nosotros. Pero dejáis atrás la tierra abierta. Ya sembrarán los otros. Si llegáis al verano, aun tendréis más fatiga al cargaros los frutos. En los días de cosecha, ¿nadie os llamó Victoria? ¿De verdad sois estériles ${ }^{39}$ ?

En este caso, tal vez el atisbo de esperanza se debe a que el poeta, en el destino de los mulos, intuye también el nuestro: «Sois cualquiera de nosotros». Pues, en efecto, no es raro que los animales incluyan, en su valor simbólico, la identidad del propio poeta. Encontramos otro ejemplo de este uso, añadido a la reflexión metapoética, en la «Canción para terminar», del poeta jerezano José Mateos. En ella, el autor repasa los instrumentos de su arte, «-acordes, palabras, signos...-», y, a la vista de su humilde punto de partida, duda de que pueda rozar el misterio más elevado: «ipretendes / que te hable el Dios prometido?». Sin embargo, la respuesta que ofrece a su propia pregunta no es unívoca, ni en un sentido afirmativo ni en el contrario:

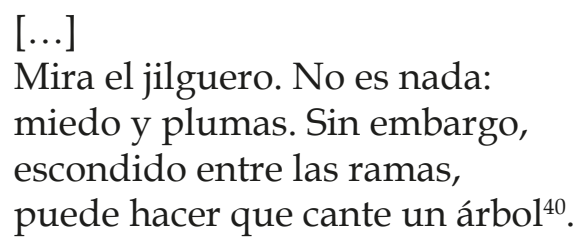

El efecto que produce el canto de un jilguero, desde su escondite entre las ramas de un árbol, no es algo que se pueda identificar, ni como símbolo ni como parábola, con la respuesta del mencionado «Dios prometido», ya que el único sonido provendría del propio pájaro. Sin embargo, dicha imagen evoca muy eficazmente una llamativa desproporción entre los medios de los que dispone el canto y el alcance que puede lograr, una desproporción que, de hecho, aparece superada en el correlato objetivo del jilguero y que, en consecuencia, lleva inevitablemente al lector a responder afirmativamente a las dudas del poeta. En la poesía de José Mateos, los pájaros aparecen con mucha frecuencia para representar esas intuiciones innominadas que se agitan en lo más hondo del alma, sin que sea posible determinar hacia dónde apuntan exactamente. En el largo poema titulado «La niebla», el propio autor ha dejado constancia de las grandes preguntas que las aves suscitan, y de las cuales ofrece unas

\footnotetext{
${ }^{39}$ Cabanillas, J. J., La luna y el sol, Sevilla, Cuadernos de Poesía Númenor, 2006, p. 28.

${ }^{40}$ Mateos, J., Reunión, Granada, La Veleta, 2006, p. 123.
} 
breves representaciones a modo de respuesta, aunque esos breves trazos no hacen sino ofrecer nuevas incógnitas:

[...]

¿Son reales los pájaros o viven

glosando el cielo azul del paraíso?

¿Son más de lo que son? ¿Son sólo eso:

ebriedad sin sentido, alarde inútil?

Y si la muerte es madre de esos seres

que amas tanto, ¿qué habrá en el paraíso

en lugar de la muerte?

La abubilla

traza en la arena un signo indescifrable.

La golondrina es otra cuando vuelve.

La alondra exalta la humildad del campo.

Oscila el junco cuando el mirlo escapa

y el ruiseñor es un asceta triste.

$[\ldots]^{41}$

En otras ocasiones, José Mateos sí hace más visible la relación entre uno de estos animales y el sentimiento que representan. En la vigésima de sus «Canciones», el autor jerezano nos describe dos gaviotas que vuelan juntas, alejándose de la tierra en dirección al mar. El poeta se pregunta por su destino: «¿Hacia qué mundo se iban, / hacia qué playas eternas [...]?». Sin embargo, la respuesta a esta interrogación es indiferente: lo sabemos al ver el estribillo de la canción, que se modula en cada una de las tres estrofas: «y quise irme con ellas», expresa en la primera, mientras que, en la segunda, nos habla de la tristeza «de querer irme con ellas». Los pájaros no son más que la materialización de un deseo, la nostalgia que tiene el poeta de otro lugar, de un destino que ni siquiera conoce. Las dos gaviotas son evocadas por el recuerdo, que revive también ese mismo deseo, al tiempo que los últimos versos de la composición hablan abiertamente de su origen, del anhelo que tiene el alma por algo más allá de este mundo:

$[\ldots]$

Qué sed del agua que huye.

Qué ansias de huir hacia fuera.

No se le olvida a mi alma

su origen y procedencia.

Por eso, si ve, en la tarde,

gaviotas que se alejan,

se estremece

y quiere irse con ellas ${ }^{42}$.

Con todas estas técnicas de distanciamiento y objetivación, la poesía española

\footnotetext{
${ }^{41}$ Mateos, J., Reunión, ob. cit., p. 157.

${ }^{42}$ Mateos, J., Reunión, ob. cit., p. 112. 
Animales y «narratividad». Dos muestras para un bestiario en la lírica de dos generaciones españolas...

contemporánea ha pretendido rehuir los excesos del intimismo. Y los animales, con su múltiple variedad de formas y actitudes, siempre nos han fascinado, de ahí que desde antiguo se les hayan atribuido valores simbólicos y propiedades especiales. Aunque la lírica de nuestro tiempo haya renunciado a tales convenciones, aún podemos encontrarlos como elementos reveladores y mensajeros de nuestra propia alma.

\section{Bibliografía}

AleiXandre, V., Poesías completas, Madrid, Visor, 2001.

Alonso, D., Hijos de la ira, Madrid, Espasa Calpe, 1991.

BArroso, E., Poesía andaluza de hoy (1950-1990), Sevilla, Biblioteca de Cultura andaluza, 1991.

Cabanillas, J. J., Palabras de demora, Sevilla, Renacimiento, 1994.

, En lugar del mundo, Valencia, Pre-Textos, 1998.

Los que devuelve el mar, Valencia, Pre-Textos, 2005.

La luna y el sol, Sevilla, Cuadernos de Poesía Númenor, 2006.

Cuenca, L. A. DE, Por fuertes y fronteras, Madrid, Visor, 1996.

García Martín, J. L., La poesía figurativa. Crónica parcial de quince años de poesía española, Sevilla, Renacimiento, 1992.

, Treinta años de poesía española, Sevilla-Granada, Renacimiento-La Veleta, 1996.

García Montero, L., Aguas territoriales, Valencia, Pre-Textos, 1996.

JIMÉNEZ, J. O., «Reafirmación, proximidad, continuidad: notas hacia la poesía española última (1975-1985)», Las nuevas letras, 3-4 (1985), pp. 40-47.

Langbaum, R., La poesía de la experiencia. El monólogo dramático en la tradición literaria moderna, trad. de Julián Jiménez Heffernan, Granada, Comares, 1996.

LANZ, J. J., «La poesía española: ¿hacia un nuevo romanticismo?», El Urogallo, 60 (1991), pp. 36-45.

, «Primera etapa de una generación. Notas para la definición de un espacio poético: 1977-1982», Ínsula, 565 (1994), pp. 3-6.

, Antología de la poesía española (1960-1975), Madrid, Espasa-Calpe, 1997.

Martínez Mesanza, J., Europa y otros poemas, Málaga, Área de Cultura de la Diputación Provincial de Málaga, 1990.

Mateos, J., Reunión, Granada, La Veleta, 2006.

MunÁrriz, J., Poética y poesía, Madrid, Fundación Juan March, 2007.

Nicolás, C., «Novísimos (1966-1988): Notas para una poética», en Ínsula, 505 (1989), pp. 11-14.

NúÑEz, A., La luz en las palabras. Antología poética, Vicente Vives Pérez (ed.), Madrid, Cátedra, 2009.

SÁnchez Rosillo, E., Las cosas como fueron, Granada, La Veleta, 1995. 
, La vida, Barcelona, Tusquets, 1996.

, La certeza, Barcelona, Tusquets, 2005.

SALVADOR, A., «The poetry of experience y la poesía española de los últimos quince años», en R. Langbaum, La poesía de la experiencia. El monólogo dramático en la tradición literaria moderna, trad. de Julián Jiménez Heffernan, Granada, Comares, 1996, pp. 8-11.

Ors, Miguel D', La aventura del orden. Poetas españoles del fin de siglo, Sevilla, Renacimiento, 1998.

, 2001 (Poesías escogidas), Sevilla, Cuadernos de Poesía Númenor, 2001.

RodríGueZ, C., «Algunos comentarios sobre el tema de la fauna en la poesía de Vicente Aleixandre», Ínsula, 374-375 (1978), p.17.

Utrera Torremocha, M. V., «Luis Cernuda en la poesía española del siglo XX», en VV. AA., A zaga de tu huella. Homenaje al profesor Cristóbal Cuevas, Málaga, Universidad de Málaga, 2005, vol. II, pp. 137-1. 